\title{
Correction to: Are two brands better than one? Investigating the effects of co-branding in advertising on audience memory
}

\section{Cathy Nguyen ${ }^{1}$ D $\cdot$ Jenni Romaniuk ${ }^{1} \cdot$ Margaret Faulkner $^{1} \cdot$ Justin Cohen $^{1}$}

Published online: 19 June 2019

(C) The Author(s) 2019

Correction to: Mark Lett (2018) 29(1):37-48

https://doi.org/10.1007/s11002-017-9444-3

The article Are two brands better than one? Investigating the effects of cobranding in advertising on audience memory, written by Cathy Nguyen, Jenni Romaniuk, Margaret Faulkner and Justin Cohen, was originally published electronically on the publisher's internet portal (currently SpringerLink) on 13 November 2017 without open access.

With the author(s)' decision to opt for Open Choice the copyright of the article changed on June 2019 to (C) The Author(s) 2019 and the article is forthwith distributed under the terms of the Creative Commons Attribution 4.0 International License (http://creativecommons.org/licenses/by/4.0/), which permits use,

The online version of the original article can be found at https://doi.org/10.1007/s11002-017-9444-3

Cathy Nguyen

Cathy.Nguyen@MarketingScience.info

Jenni Romaniuk

Jenni.Romaniuk@MarketingScience.info

Margaret Faulkner

Margaret.Faulkner@ MarketingScience.info

Justin Cohen

Justin.Cohen@MarketingScience.info

1 Ehrenberg-Bass Institute-University of South Australia, 70 North Terrace, Adelaide,

SA 5000, Australia 
duplication, adaptation, distribution and reproduction in any medium or format, as long as you give appropriate credit to the original author(s) and the source, provide a link to the Creative Commons license and indicate if changes were made.

The original article has been corrected.

Open Access This article is distributed under the terms of the Creative Commons Attribution 4.0 International License (http://creativecommons.org/licenses/by/4.0/), which permits unrestricted use, distribution, and reproduction in any medium, provided you give appropriate credit to the original author(s) and the source, provide a link to the Creative Commons license, and indicate if changes were made.

Publisher's note Springer Nature remains neutral with regard to jurisdictional claims in published maps and institutional affiliations. 